\title{
Diminished error-related negativity and error positivity in children and adults with externalizing problems and disorders: a meta-analysis on error processing
}

\author{
Miranda Christine Lutz, MSc; Rianne Kok, PhD; Ilse Verveer, PhD; Marcelo Malbec, BSc; \\ Susanne Koot PhD; Pol A.C. van Lier, PhD; Ingmar H.A. Franken, PhD
}

\begin{abstract}
Background: Deficits in error processing are reflected in an inability of people with externalizing problems to adjust their problem behaviour. The present study contains 2 meta-analyses, testing whether error processing - indexed by the event-related potentials errorrelated negativity $(\mathrm{ERN})$ and error positivity $(\mathrm{Pe})$ - is reduced in children and adults with externalizing problems and disorders compared to healthy controls. Methods: We conducted a systematic search in PubMed (1980 to December 2018), Psyclnfo (1980 to December 2018) and Scopus (1970 to December 2018), identifying 328 studies. We included studies that measured error processing using the Eriksen flanker task, the go/no-go task or the stop-signal task in healthy controls and in adults or children with clearly described externalizing behavioural problems (e.g., aggression) or a clinical diagnosis on the externalizing spectrum (e.g., addiction). Results: Random-effect models (ERN: 23 studies, 1739 participants; Pe: 27 studies, 1456 participants) revealed a reduced ERN amplitude (Hedges' $\mathrm{g}=0.44,95 \%$ confidence interval $[\mathrm{Cl}] 0.29$ to 0.58 ) and a reduced Pe amplitude (Hedges' $g=-0.27,95 \% \mathrm{Cl}-0.44$ to -0.09 ) during error processing in people with externalizing problems or disorders compared to healthy controls. Type of diagnosis, age and the presence of performance feedback or comorbidity did not moderate the results. The employed cognitive task was a moderator for Pe but not for ERN. The go/no-go task generated a greater amplitude difference in Pe than the Eriksen flanker task. Small-sample assessment revealed evidence of publication bias for both event-related potentials. However, a $p$ curve analysis for ERN showed that evidential value was present; for $\mathrm{Pe}$, the $p$ curve analysis was inconclusive. Limitations: The moderators did not explain the potential heterogeneity in most of the analysis, suggesting that other disorder- and patient-related factors affect error processing. Conclusion: Our findings indicate the presence of compromised error processing in externalizing psychopathology, suggesting diminished activation of the prefrontal cortex during performance monitoring.
\end{abstract}

\section{Introduction}

Externalizing problem behaviour has been associated with problems in cognitive control, ${ }^{1}$ of which error processing is an important component. ${ }^{2,3}$ People with externalizing problems or disorders are characterized by disruptive and problematic behaviour that is directed outward to the environment and are further referred to as externalizing samples. Specific diagnoses and behaviours that belong to the category of externalizing samples include attention-deficit/hyperactivity disorder (ADHD), oppositional defiant disorder, psychopathy, conduct disorder, aggression, antisocial personality disorder, substance use disorder (SUD) and delinquency. ${ }^{4}$ Error-processing, which refers to the ability to detect errors and evaluate performance, allows for the adaptation of behaviour to correctly react to stimuli from the environment. ${ }^{5}$ Deficits in error processing can be reflected in a failure to adjust behaviour, which is indicative of externalizing psychopathology. Deficits in error processing can be detected by electroencephalography (EEG) and are reflected in a diminished amplitude of the event-related potentials (ERP) error-related negativity (ERN) and error positivity (Pe). Several studies have investigated differences in the ERN (e.g., $\mathrm{Lo}^{6}$ in children and adolescents with externalizing problem behaviour) and Pe (e.g., Luijten and colleagues ${ }^{7}$ in substance use disorder), but a systematic review is lacking in children and adults that combines externalizing samples and

Correspondence to: Miranda C. Lutz-Landesbergen, Erasmus University Rotterdam, Department of Psychology, Education \& Child Studies, Burgemeester Oudlaan 50, Rotterdam Zuid-Holland 3000 DR, Netherlands; lutz@essb.eur.nl

Submitted Feb. 13, 2020; Revised Jul. 3, 2020; Accepted Jul. 4, 2021

Cite as: J Psychiatry Neurosci 2021 November 9;46(6). doi: 10.1503/jpn.200031 
includes comparison with healthy controls. This study investigates the ERN and Pe across different externalizing samples to determine error processing deficits in children and adults with externalizing problems or disorders compared to healthy controls.

\section{Error-related negativity}

The $\mathrm{ERN}^{8,9}$ (or negativity error; $\left.\mathrm{Ne}\right)^{10}$ is a negative deflection that occurs approximately $50 \mathrm{~ms}$ to $100 \mathrm{~ms}$ after commission of an error. ${ }^{11,12}$ This ERP waveform peaks at the frontocentral electrodes, reflecting the neuronal activity of the anterior cingulate cortex ${ }^{13}$ during error processing. ${ }^{3,5,14}$ The ERN is a robust and reliable ${ }^{15,16}$ neurobiological marker that reflects the brain's initial reaction to an error and the start of error processing, whether or not the person is conscious of the error. ${ }^{17,18}$ Several theories outline the functional significance of the ERN (for an overview, see Loo and colleagues ${ }^{19}$ and Olvet and $\mathrm{Hajcak}^{20}$ ), including mismatch theory, motivational significance theory, reinforcement and learning-based theory, and conflict monitoring theory. These theories describe different processes of error and conflict detection, as well as the role of the dopaminergic system of the brain and the anterior cingulate cortex. Previous work has suggested that the ERN can serve as a candidate endophenotype for psychopathology, especially for internalizing disorders. Meta-analyses of internalizing samples show that the ERN appears to be increased in patients with anxiety, ${ }^{21}$ obsessivecompulsive disorder ${ }^{22}$ and depression disorders ${ }^{23}$ compared to healthy controls. A recent meta-analysis concluded that the ERN can serve as a transdiagnostic marker for internal and externalizing disorders. ${ }^{24}$ The current study is an extension of this meta-analysis, including child samples as well as adult samples, and also including psychopathy samples. In addition, we have used effect size calculation rather than effect size estimation, and included the late error processing component Pe as well as the ERN.

Deviating activation patterns in the brain with respect to cognitive control have been found in externalizing behaviour. $^{20,25}$ Some studies have reported decreased ERN amplitude in ADHD (e.g., Wiersema and colleagues ${ }^{26}$ ) and addiction (e.g., Zhou and colleagues ${ }^{27}$ ), but other reports have found no differences in the ERN compared to healthy controls (e.g., in addiction ${ }^{28}$ and $\mathrm{ADHD}^{29}$ ). Some studies have even reported increased ERN amplitude in $\mathrm{ADHD}^{30}$ and addiction ${ }^{31}$ compared to controls. The presence of comorbid internalizing problems has been suggested as a possible explanation for these mixed results, as illustrated by the study of Schellekens and colleagues ${ }^{31}$ in a sample of patients with alcohol dependence. Although medication (e.g., Groom and colleagues $^{32}$ ), age ${ }^{6}$ and the experimental paradigm ${ }^{15}$ have been studied as moderating factors for ERN amplitude, it remains unclear whether these variables influence ERN results across externalizing samples. Furthermore, several studies have reported that performance feedback during tasks can influence error processing. ${ }^{33-35}$ When participants receive feedback on performance, they become cautious of their response accuracy, inducing greater reactions to errors.
By conducting a meta-analysis, we were able to integrate inconsistent findings to shed light on the role of the ERN in externalizing behaviours. Moreover, by explicitly testing medication use, age, comorbidity, experimental paradigm and performance feedback as moderators, we were able to investigate whether or how they account for variability in ERN studies.

\section{Error positivity}

Another ERP component relevant for performance monitoring is Pe amplitude. The Pe is a slow, positive deflection, peaking at approximately $200 \mathrm{~ms}$ to $600 \mathrm{~ms}$ after an error; it is measured across the centroparietal area. ${ }^{10,36,37}$ The Pe is said to reflect the conscious awareness of errors and error processing. ${ }^{37}$ It is an independent ERP component, despite the fact that it follows directly after the ERN and shows similarities with the P300 component (for example, the latency window). (For further reading on the similarities and differences between these components, see Arbel and Donchin, ${ }^{36}$ Overbeek and colleagues, ${ }^{37}$ Davies and colleagues ${ }^{38}$ and Ridderinkhof and colleagues..$^{39}$ ) The functional significance of the Pe has been described in several hypotheses, ${ }^{12,37}$ including the affective processing hypothesis (in which the Pe reflects the emotional appraisal of the error), the behaviour-adaptation hypothesis (in which the Pe indicates performance adjustment after error) and the error awareness hypothesis (in which the Pe reflects the conscious recognition of the error committed). Although empirical evidence is needed to support these hypotheses (specifically in terms of the neural generators of $\mathrm{Pe}$ ), they suggest that diminished Pe could be related to deviant activity of the rostral part of the anterior cingulate cortex. ${ }^{14,40}$

Compared to controls, Pe reductions in error processing for people with externalizing problems or disorders have been observed more consistently than ERN reductions, although some discrepancies have been found across studies. For instance, some studies have found diminished Pe amplitudes in people with ADHD (e.g., Albrecht and colleagues ${ }^{41}$ ) and substance use (e.g., Franken and colleagues ${ }^{42}$ ), but these were not replicated in subsequent studies (e.g., addiction studies ${ }^{28,43}$ ). Moreover, other studies have found a reverse effect, indicating that increased Pe amplitudes are related to externalizing behaviour (e.g., in addiction ${ }^{44}$ and $\mathrm{ADHD}^{45}$ ). This is the first meta-analysis to summarize Pe findings in externalizing samples compared to healthy controls. We have examined the moderators suggested for the ERN, above, to try to better understand these discrepancies in study findings.

In the current study, we aimed to investigate whether the ERN and Pe were different in children and adults with externalizing problems or disorders compared to healthy controls. We use meta-analysis and focused on the mean amplitude of the ERN at the midline frontocentral electrode (FCz; for subsequent analyses to investigate the effect of other midline electrode sites $\mathrm{Fz}$ and $\mathrm{Cz}$, see Appendix 1, available at jpn.ca) and the Pe at the midline central electrode $(\mathrm{Cz})$. We expected that both the ERN and Pe amplitudes would be reduced in the externalizing groups, indicating deficits in error processing. To explain the mixed results found in this field of 
research, we investigated potential heterogeneity by adding type of diagnosis, presence of comorbidity, experimental paradigm, age and medication use as moderators in both analyses. Except for comorbidity (comorbid internalizing or externalizing symptoms or a combination of both) and performance feedback, we expected that the moderators would not influence ERP amplitudes. We did not expect that effect size variability would be explained by the experimental paradigm, because these tasks often elicit highly correlated amplitudes and have high construct validity. ${ }^{15,46}$ In cases of comorbidity, we expected that differences in ERN and Pe between the clinical and control groups would be smaller for samples that had internalizing comorbid symptoms, and greater for samples with externalizing symptoms. We also expected that the presence of performance feedback would elicit a greater ERN and Pe than no performance feedback.

\section{Methods}

We did not preregister this study, but to enhance reproducibility and accommodate the open science community, our data and code are available at the Open Science Framework (https://osf.io/dkxtp/). We determined a search strategy and inclusion and exclusion criteria before our literature search. Secondary to the steps undertaken as described in this report, we reviewed the relevant literature, ${ }^{47}$ consulted experts and compiled study-related factors to ensure that we were informed about the state of art in this field. We intended to identify as many EEG studies that evaluated ERN and Pe magnitudes in case-control (externalizing samples v. healthy volunteers) studies.

\section{Search strategy}

We conducted the literature search using 3 databases: PsycInfo (1980 to December 2018), PubMed (1980 to December 2018) and Scopus (1970 to December 2018). Search terms included the following: inhibit*, cognitive or inhibitory control, error processing or monitoring, external* symptoms, disorders and problems, alcohol, cocaine, stimulants, heroin, smoking, cannabis, substance abuse, substance use-, dependence-, misuse, alcoholism, ADHD, ADD, antisocial personality disorder, oppositional defiant disorder, aggression, psychopathy, intermittent explosive disorder, conduct disorder, antisocial behaviour, behavioural problems or disorders, psychopathic traits and callous-unemotional traits. We cross referenced the above terms with the following: error-related negativity, error positivity, ERP, EEG, Eriksen flanker task, go/no-go task and stop-signal task. For complete search strategy queries by database, see Appendix 1.

\section{Eligibility criteria}

We assessed studies identified from the literature search, together with studies identified from other sources, according to the following inclusion criteria: studies were published in peer-reviewed journals in English and performed in human volunteers of any age; studies addressed error processing using the EEG components ERN (at Fz, FCz and $\mathrm{Cz}$ ) or Pe $(\mathrm{Cz})$, irrespective of the latency window; the ERN and Pe were measured during the Eriksen flanker task, ${ }^{48}$ the go/nogo task or the stop-signal task; studies included a healthy control group of participants with no clinical or neurologic diagnosis; and participants in the patient groups were recruited because they had a clinical diagnosis of an externalizing disorder (based on the Diagnostic and Statistical Manual of Mental Disorders, fifth edition [DSM-5] or the International Classification of Diseases, 10th revision [ICD-10], or earlier versions) or they showed subclinical levels of externalizing problems. Studies were excluded according to the following criteria: means and standard deviations of the ERN or Pe amplitude for both groups (derived from averaging ERN and Pe epochs where the peak was the maximum from error trials) were unavailable from the published report or after contact with the authors; studies used adjusted paradigms (e.g., lack of neutral stimuli presented) or stimuli that were not presented visually; and studies used the continuous performance task or error awareness task (despite including go/no-go elements).

\section{Data extraction}

Records identified through the literature search were imported to Mendeley. In this program, we screened titles and abstracts using our inclusion criteria. To avoid unwanted exclusion, all articles in which the abstract did not contain full information were kept for further reading. Next, we downloaded and read the full text of articles that had passed the screening stage, and we reviewed their reference lists to identify additional studies for potential inclusion. The first author (ML) extracted relevant information from the included studies, retrieving sample characteristics such as sample size, age, sex ratio, disorder (ADHD, addiction or other externalizing disorders), condition (clinical v. subclinical), the presence of comorbidity (if known, coding for externalizing, internalizing or mixed problems), the use of medication and pretesting group differences. We assessed patients' diagnostic status (clinical or subclinical) by extracting the diagnostic tools used (DSM III or IV or ICD-10) and details about the informants (specialist, self-report, parent, teacher, or medical or legal reports). A study was considered clinical when the diagnosis was obtained by a trained psychologist or psychiatrist, or when participants were recruited from inpatient treatment facilities. Offenders incarcerated for serious crimes were also considered to be clinical. We categorized the studies into 5 diagnosis groups: child and adult ADHD, clinical and subclinical addiction (adults only) and "other." Studies with samples of offenders, people with multi-problem behaviour and people with high scores on psychopathy or aggression measures were considered "other," leaning toward a sample with forensic characteristics. Participants were considered subclinical when no diagnosis was determined, but when diagnostic tools or selfreports indicated heightened levels of externalizing problems. To be included in the final analysis, the eligible study had to report a cut-off score or level for the diagnostic tool. People were considered healthy controls when no 
clinical or neurologic diagnosis or disabilities were reported. Comorbidity was coded as any co-occurring symptom or (sub)clinical level of other internalizing (e.g., anxiety) or externalizing (e.g., conduct) problems.

We also gathered information about the experiment, including the cognitive task used, whether the task was adjusted (e.g., instructions the participants received) and latency windows. For studies that used multiple experimental manipulations, we systematically selected the first or baseline time point, the neutral stimuli trials and, when multiple tasks were presented, the Eriksen flanker task. We requested the mean and standard deviation of ERN and Pe amplitudes of error trials by contacting authors when articles did not provide this information. We also requested unpublished data, but those requests did not lead to viable data for our analysis.

Two authors (I.V. and M.M.) independently extracted information from the manuscripts to verify the work of the first author. For categorical variables, Cohen's $\kappa$ was between 0.79 and 0.81 , indicating strong level of agreement. For continuous variables, intraclass correlation was between 0.97 and 0.99, which was near-perfect agreement. We evaluated the selected studies primarily on their choice of sample and their experimental design. We (M.L., I.V., M.M. and I.F.) discussed whether the selected studies adhered to our inclusion and exclusion criteria and whether they were similar enough to be compiled.

\section{Data analysis and small sample bias assessment}

For both the ERN and Pe meta-analyses, we assumed a random model because of variance in the estimates due to different clinical disorders and experimental tasks administered. ${ }^{49}$ We used restricted maximum likelihood estimation to estimate between-study variance. ${ }^{50}$ As recommended by Veroniki and colleagues, ${ }^{51}$ we ran analyses with the DerSimonianLaird and Sidik and Jonkman estimators to determine sensitivity, but restricted maximum likelihood estimation resulted in a better model fit. We computed standardized mean difference (SMD; Hedges' $g^{52}$ ) from the means and variances of the ERN and Pe amplitudes, including factor $J$ to reduce overestimation of the bias induced by small sample sizes. For studies with multiple externalizing groups, we adjusted the weights appointed to effect sizes by splitting the $N$ of the control group. ${ }^{53}$ This was to avoid unit-of-analysis errors or doublecounting problems evoked by multiple testing of the control groups. For the ERN, a positive SMD indicated reduced amplitude for the externalizing group. For the $\mathrm{Pe}$, a negative SMD indicated reduced amplitude for the externalizing group. Both SMDs indicated a diminished electrocortical reaction after the error. Effect sizes of 0.2 to 0.3 were considered small; effect sizes of approximately 0.5 were considered medium; and effect sizes of 0.8 and higher were considered large. ${ }^{54}$ We investigated influential or outlier studies based on the recommendations of Viechtbauer and Cheung. ${ }^{55} \mathrm{We}$ evaluated the degree of heterogeneity using $I^{2}$, where a larger value indicated increasing variety in effect sizes. ${ }^{56,57}$ We performed subgroup or moderation analyses when heterogeneity
(Cochran's $Q$ ) was significant. Moderation analyses for clinical disorder, comorbidity, medication use, experimental task and a meta-regression of age were determined a priori. Reviewers also suggested that we test the effect of performance feedback and electrode site (Appendix 1, section 4) as additional moderators.

We examined small sample study bias by assessing asymmetry in funnel plots, applying Egger's test of the intercept $t^{58}$ and Duval and Tweedie's trim-and-fill procedure. ${ }^{59}$ To detect whether small samples distorted the funnel plots created using SMD, ${ }^{60}$ we performed a sensitivity analysis using adjusted funnel plots with $1 \sqrt{ } n$ on the $y$ axis as a precision estimate, rather than the standard error. In the end, the adjusted funnel plots also detected asymmetry as a result of publication bias, not only small sample size. We also evaluated the robustness of the effects we found with the fail-safe $N$ calculation using the Orwin approach. ${ }^{61}$ However, these assessments have their limitations, ${ }^{62}$ so we also performed a $p$ curve analy$\operatorname{sis}^{62-65}$ (Appendix 1, section 5) to inspect whether significant $p$ values $\left(p<0.05^{62}\right)$ provided proof of evidential value (for a full description and application of this assessment, see Harrer and colleagues ${ }^{53}$ ). As recommended by van Aert and colleagues, ${ }^{66}$ a $p$ curve analysis is conducted only when $I^{2}$ is less than $50 \%$ and studies' effects are in one direction, to allow for robust conclusions. All analyses were performed in R (version 1.3.959), using meta (version 4.12.0), ${ }^{67}$ metafor (version 2.4.0) ${ }^{68}$ and dmetar (version 0.0.9000), ${ }^{53}$ guided by the instructions of Harrer and colleagues. ${ }^{53}$ All significance tests were conducted at a significance level of $5 \%$.

\section{Results}

\section{Selected studies}

Figure 1 shows a flow chart of the literature search. Where applicable and possible, we adhered to PRISMA guidelines (Appendix 1, section 2). The search of databases and additional sources yielded a total of 328 records. After removing duplicates and reviews $(n=71)$, we screened the abstracts of 257 studies. We then assessed the full text of the 82 articles that met our inclusion criteria. We included 31 articles for qualitative analysis, of which 23 were ERN studies at the $\mathrm{FCz}$ electrode (27 effect sizes; $n=1739$ ) and 27 were Pe studies at the $\mathrm{C} z$ electrode ( 31 effect sizes; $n=1456$ ). We found no studies that used the stop-signal task. Descriptive information for the included studies is shown in Table 1; further details of the included studies are shown in Appendix 1.

\section{ERN summary effect}

The ERN meta-analysis included 23 studies and 1739 participants. We found a small to medium overall effect size $(g=$ $0.44,95 \%$ CI 0.29 to $0.58, p<0.01$ ). This indicated that in the patient group, the ERN had a decreased negative amplitude compared to healthy controls. Between-study variability was $36 \%$, indicating a low to moderate amount of variability in effect sizes. The test for heterogeneity was significant $\left(Q_{26}=\right.$ $40.69, p=0.03$ ), which gave us cause to perform moderation 
analysis. We identified the studies of Sokhadze and colleagues $^{87}$ (high effect size) and Michelini and colleagues ${ }^{84}$ (large sample size) as influential cases. However, we kept these studies in the overall analysis because they did not influence the overall model. A forest plot for the ERN is presented in Figure 2.

\section{ERN subgroup analyses}

Moderation analyses revealed no significant difference in ERN amplitudes between diagnosis groups $\left(Q_{4}=0.66, p=\right.$ 0.96). Comorbidity did not significantly influence the ERN amplitudes $\left(Q_{3}=5.11, p=0.16\right)$, and the type of experimental paradigm was not a moderator $\left(Q_{1}=0.01, p=0.91\right)$. The presence of performance feedback also did not account for variability in ERN effect size $\left(Q_{1}=0.08, p=0.78\right)$. We had initially intended to test the effect of medication, but this variable was confounded in the sample of ADHD participants, making further investigation futile. For study details, see Appendix 1 (medication, section 4; electrode site, section 5). Table 2 provides an overview of the moderation results for the categorical variables. A meta-regression with age as a predictor revealed that age was not associated with the effect sizes $\left(F_{1,25}=\right.$ 2.30, $p=0.14)$.

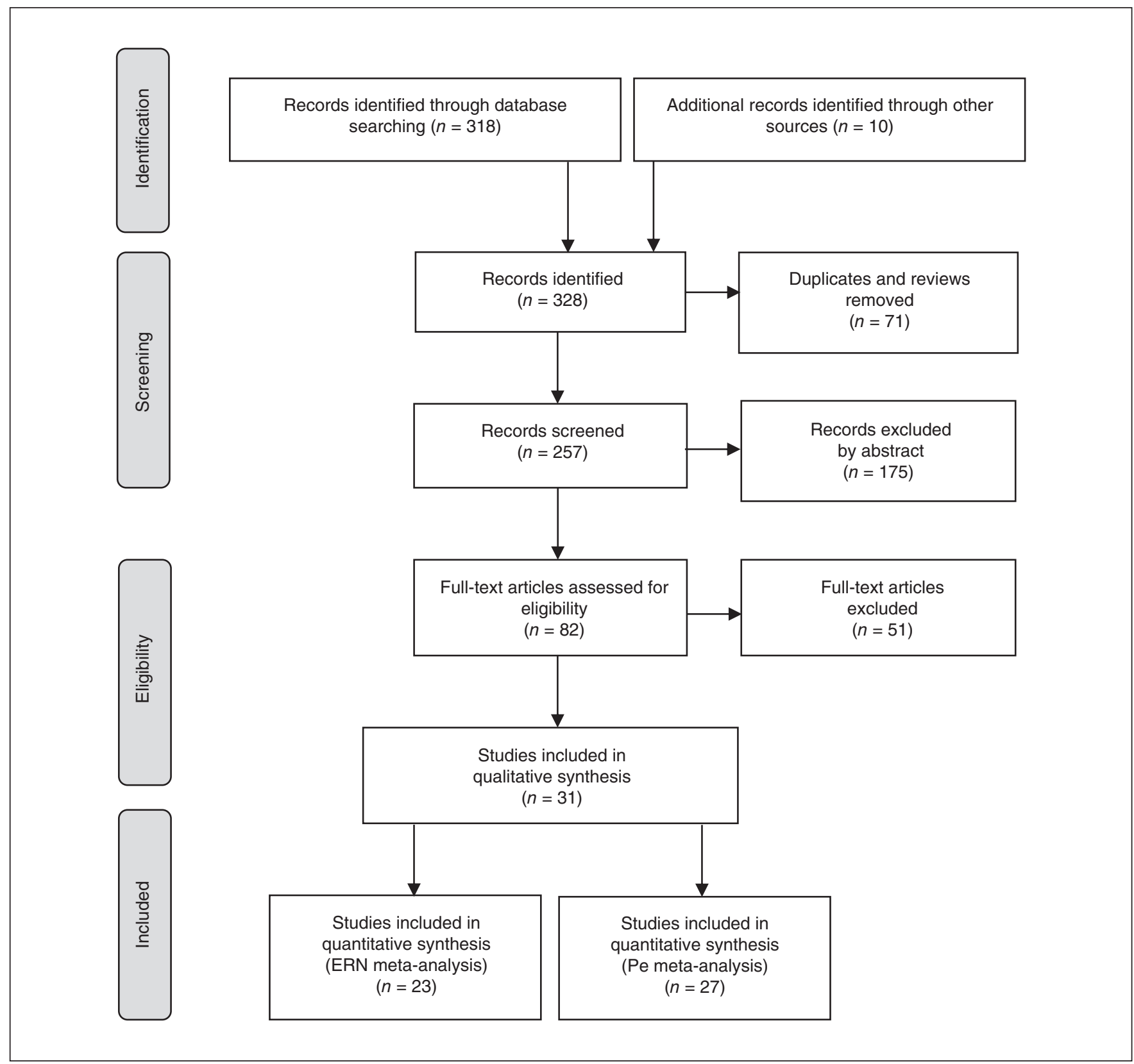

Figure 1: PRISMA flow diagram. ERN = error-related negativity; Pe = error positivity; PRISMA = Preferred Reporting Items for Systematic Reviews and Meta-Analyses. 


\section{ERN small sample study bias}

To investigate publication bias, we visually inspected the funnel plots of the effect sizes. The Egger's intercept of the funnel plot was significant $(B=2.09, p=0.03)$, indicating evidence of publication bias. The funnel plot in Figure 3 applies Duval and Tweedie's trim-and-fill procedure. Application of this procedure revealed that by filling 7 studies, the overall effect would be reduced to small ( $g=0.29,95 \%$ CI 0.12 to $0.45, p=0.001)$, indicating the presence of bias. Despite this bias, 27 studies were needed to get to an unweighted average effect size of 0.24 using the fail-safe $N$ test. However, a $p$ curve analysis $(k=9)$ revealed the presence of right skewness of the significant $p$ values, and of evidential value (half: $Z=-2.33, p=0.009$; full: $Z=-1.43, p=$ 0.08 ). The flatness test was not significant (half: $Z=2.73, p=0.99$; full $Z=-0.32, p=0.37$ ). Although the analysis was

Table 1: Characteristics of included studies

\begin{tabular}{|c|c|c|c|c|c|c|c|c|c|}
\hline \multirow[b]{2}{*}{ Study } & \multirow[b]{2}{*}{ ERP } & \multirow[b]{2}{*}{ Diagnosis } & \multirow[b]{2}{*}{ Comorbidity* } & \multirow{2}{*}{$\begin{array}{l}\text { Experimental } \\
\text { paradigm }\end{array}$} & \multicolumn{2}{|c|}{ Sample size, $n$} & \multirow[b]{2}{*}{$\%$ Male } & \multicolumn{2}{|c|}{ Mean age $\pm S D, y r$} \\
\hline & & & & & Ext & Con & & Ext & Con \\
\hline Albrecht et al. ${ }^{41}$ (2008) & Both & Child ADHD & Yes, mix & Flanker & 68 & 22 & 100 & $11.3 \pm 1.6$ & $11.2 \pm 1.7$ \\
\hline Balogh et al. ${ }^{69}$ (2017) & Both & Adult ADHD & Yes, int & Go/no-go & 26 & 14 & 78 & $26.7 \pm 5.7$ & $31.5 \pm 11.4$ \\
\hline Brazil et al. ${ }^{70}(2009)$ & Both & $\begin{array}{l}\text { Other: violent } \\
\text { offenders }\end{array}$ & No & Flanker & 16 & 18 & 100 & $39 \pm 9.5$ & $37 \pm 6.4$ \\
\hline Chang et al. ${ }^{71}$ (2009) & Both & Adult ADHD & Yes, mix & Flanker & 36 & 32 & 50 & $23.7 \pm 3.7$ & $23.7 \pm 3.7$ \\
\hline Chen et al. ${ }^{72}$ (2013) & ERN & Clinical addiction & No & Flanker & 20 & 15 & 100 & $37.1 \pm 9.5$ & $32.5 \pm 10$ \\
\hline Czobor et al. ${ }^{73}(2017)$ & $\mathrm{Pe}$ & Adult ADHD & No & Go/no-go & 22 & 29 & 71 & $30.6 \pm 9.7$ & $30.1 \pm 9$ \\
\hline Franken et al. ${ }^{42}$ (2007) & Both & Clinical addiction & No & Flanker & 14 & 13 & 78 & $38.1 \pm 10.2$ & $32 \pm 13.8$ \\
\hline Franken et al. ${ }^{74}$ (2010) & $\mathrm{Pe}$ & Subclinical addiction & No & Flanker & 23 & 28 & 48 & $21.7 \pm 2.7$ & $21.3 \pm 2.8$ \\
\hline Franken et al. ${ }^{28}(2017)$ & Both & Subclinical addiction & No & Flanker & 48 & 49 & 49 & $23.4 \pm 10$ & $11.9 \pm 8.5$ \\
\hline Franken et al. ${ }^{75}$ (2018) & Both & Subclinical addiction & No & Flanker & 34 & 34 & 12 & $19.9 \pm 1.7$ & $20.8 \pm 3$ \\
\hline Groom et al. ${ }^{76}(2010)$ & Both & Child ADHD & Yes, ext & Go/no-go & 23 & 19 & 74 & $16.2 \pm 0.3$ & $16.1 \pm 2$ \\
\hline Groom et al. ${ }^{32}(2013)$ & ERN & Child ADHD & Yes, mix & Go/no-go & 28 & 28 & 96 & $12.5 \pm 1.8$ & $12.5 \pm 1.8$ \\
\hline Hermann et al. ${ }^{77}$ (2010a) & $\mathrm{Pe}$ & Adult ADHD & No & Flanker & 17 & 9 & 50 & $25.2 \pm 4.4$ & $24.2 \pm 3.1$ \\
\hline Hermann et al. ${ }^{77}$ (2010b) & $\mathrm{Pe}$ & Adult ADHD & No & Flanker & 17 & 9 & 56 & $40.0 \pm 6.8$ & $39.7 \pm 6.6$ \\
\hline Jonkman et al. ${ }^{78}$ (2007) & $\mathrm{Pe}$ & Child ADHD & No & Flanker & 10 & 10 & NA & $9.5 \pm 2.1$ & $10.76 \pm 1.2$ \\
\hline Littel et al. ${ }^{79}$ (2012) & Both & Subclinical addiction & No & Go/no-go & 25 & 27 & 63 & $20.5 \pm 3$ & $21.42 \pm 2.6$ \\
\hline Luijten et al. ${ }^{43}(2011)$ & Both & Subclinical addiction & No & Flanker & 13 & 14 & 70 & $20.7 \pm 1.3$ & $21.4 \pm 2.6$ \\
\hline Maij et al. ${ }^{80}(2017 a)$ & Both & Clinical addiction & Yes, ext & Flanker & 35 & 39 & 76 & $21.7 \pm 2.1$ & $22.1 \pm 2.1$ \\
\hline Maij et al. ${ }^{80}(2017 b)$ & Both & Clinical addiction & Yes, ext & Flanker & 38 & 39 & 68 & $21.4 \pm 2.5$ & $22.1 \pm 2.1$ \\
\hline Marhe et al. ${ }^{81}(2013)$ & Both & Clinical addiction & No & Flanker & 49 & 23 & 84 & $39.6 \pm 8.4$ & $39.9 \pm 9.4$ \\
\hline Marquardt et al. ${ }^{82}$ (2018) & Both & Adult ADHD & Yes, mix & Flanker & 27 & 28 & 51 & $35.3 \pm 8.8$ & $33.4 \pm 7$ \\
\hline McLoughlin et al. ${ }^{83}(2009 a)$ & Both & Adult ADHD & No & Flanker & 21 & 20 & 100 & $32.5 \pm 5.8$ & $30 \pm 6.5$ \\
\hline McLoughlin et al. ${ }^{83}(2009 b)$ & Both & Adult ADHD & No & Flanker & 20 & 20 & 100 & $45.9 \pm 4.2$ & $30 \pm 6.5$ \\
\hline Michelini et al. ${ }^{84}$ (2016a) & Both & Adult ADHD & Yes & Flanker & 87 & 169 & 67 & $18.3 \pm 3$ & $18.8 \pm 2.2$ \\
\hline Michelini et al. ${ }^{84}(2016 b)$ & Both & Adult ADHD & Yes & Flanker & 23 & 169 & 79 & $18.3 \pm 3$ & $18.8 \pm 2.2$ \\
\hline Morie et al. ${ }^{85}(2014)$ & Both & Clinical addiction & Yes, ext & Go/no-go & 23 & 27 & 72 & $44 \pm 6.6$ & $4.1 \pm 8.5$ \\
\hline Munro et al. ${ }^{86}(2007)$ & Both & $\begin{array}{l}\text { Other: violent } \\
\text { offenders }\end{array}$ & No & Flanker & 15 & 15 & 100 & $45.9 \pm 13.6$ & $46.6 \pm 6.9$ \\
\hline Rass et al. ${ }^{44}(2014 a)$ & Both & Clinical addiction & No & Flanker & 22 & 15 & 52 & $27.2 \pm 5.3$ & $25.2 \pm 4.3$ \\
\hline Rass et al. ${ }^{44}$ (2014b) & Both & Subclinical addiction & No & Flanker & 31 & 15 & 43 & $23.9 \pm 4.4$ & $25.2 \pm 4.3$ \\
\hline Sokhadze et al. ${ }^{87}$ (2008) & ERN & Clinical addiction & Yes, int & Flanker & 19 & 15 & 56 & $42.1 \pm 5.5$ & $37 \pm 9.4$ \\
\hline Vilà-Balló et al. ${ }^{88}$ (2014) & Both & $\begin{array}{l}\text { Other: violent } \\
\text { offenders }\end{array}$ & No & Flanker & 17 & 17 & 100 & $18.3 \pm 0.3$ & $18.6 \pm 0.3$ \\
\hline Wiersema et al. ${ }^{30}(2005)$ & $\mathrm{Pe}$ & Child ADHD & Yes, ext & Go/no-go & 22 & 15 & 65 & $10.3 \pm 1.6$ & $10.2 \pm 2$ \\
\hline Wiersema et al. ${ }^{26}(2009)$ & $\mathrm{Pe}$ & Child ADHD & Yes, mix & Go/no-go & 23 & 19 & 57 & $29.3 \pm 11$ & $30.9 \pm 11$ \\
\hline Wild-Wall et al. ${ }^{45}$ (2009) & Both & Child ADHD & Yes, int & Flanker & 15 & 12 & 71 & $13.0 \pm 1.6$ & $13.2 \pm 1.5$ \\
\hline Xue et al. ${ }^{89}(2017)$ & $\mathrm{Pe}$ & Other: aggression & No & Go/no-go & 13 & 14 & 44 & $21.3 \pm 0.9$ & $21.3 \pm 1.3$ \\
\hline Zhang et al. ${ }^{90}$ (2009) & $\mathrm{Pe}$ & Child ADHD & No & Go/no-go & 16 & 16 & NA & $7.5 \pm 1.4$ & $7.6 \pm 1.8$ \\
\hline Zijlmans et al. ${ }^{91}$ (2019) & Both & $\begin{array}{c}\text { Other: } \\
\text { multi-problem }\end{array}$ & Yes, ext & Flanker & 119 & 26 & 100 & $22.5 \pm 2.4$ & $23.1 \pm 2.6$ \\
\hline
\end{tabular}

$\mathrm{ADHD}=$ attention-deficit/hyperactivity disorder; con = control; ERN = error-related negativity; ERP = event-related potential; ext = externalizing; int = internalizing, mix = both externalizing and internalizing; NA = not applicable (not measured or unknown); $\mathrm{Pe}=$ error positivity; $\mathrm{SD}=$ standard deviation.

${ }^{*}$ Comorbid diagnosis or symptoms. 


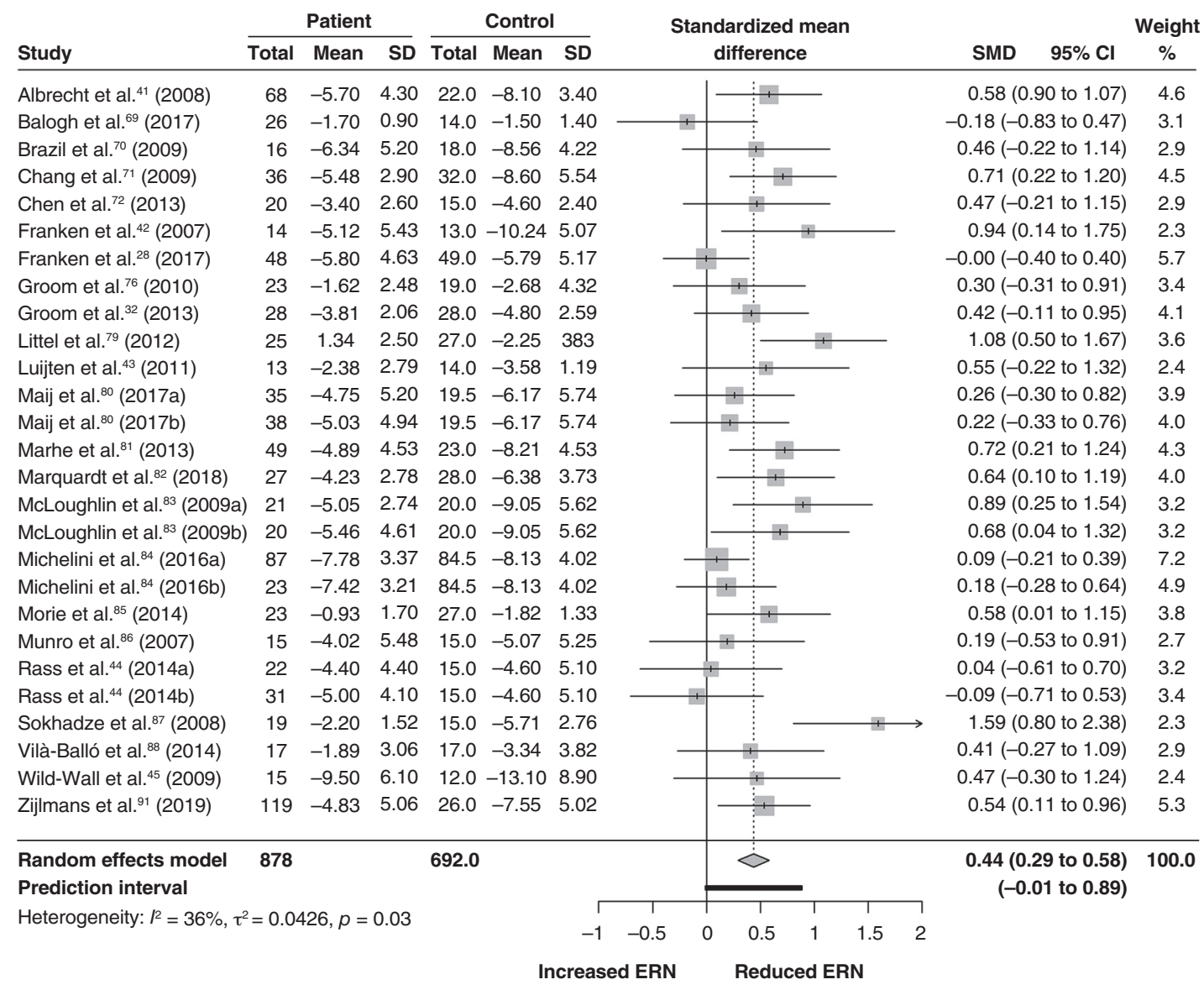

Figure 2: Overall ERN meta-analysis, including a forest plot. $\mathrm{Cl}=$ confidence interval; $\mathrm{ERN}=$ error-related negativity; $\mathrm{SD}=$ standard deviation; $\mathrm{SMD}=$ standardized mean difference.

Table 2: Results of multiple moderator analyses for ERN

\begin{tabular}{|c|c|c|c|c|c|}
\hline \multirow[b]{2}{*}{ Moderator } & \multirow[b]{2}{*}{ Category $(k)$} & \multicolumn{4}{|c|}{ ERN } \\
\hline & & SMD $(95 \% \mathrm{Cl})$ & $Q$ & $1^{2}$ & $p$ value \\
\hline \multirow{5}{*}{$\begin{array}{l}\text { Clinical diagnosis } \\
\text { group }\end{array}$} & Child ADHD (4) & $0.46(0.26$ to 0.65$)$ & 0.51 & $0 \%$ & 0.92 \\
\hline & Adult ADHD (7) & $0.40(0.05$ to 0.75$)$ & 13.69 & $56 \%$ & 0.03 \\
\hline & Clinical addiction (8) & 0.56 (0.18 to 0.94$)$ & 12.93 & $46 \%$ & 0.07 \\
\hline & Subclinical addiction (4) & $0.36(-0.51$ to 1.24$)$ & 11.03 & $73 \%$ & 0.01 \\
\hline & Other (4) & $0.44(0.22$ to 0.67$)$ & 0.67 & $0 \%$ & 0.88 \\
\hline \multirow[t]{4}{*}{ Comorbidity } & Yes, mixed (5) & 0.58 (0.43 to 0.73$)$ & 0.76 & $0 \%$ & 0.94 \\
\hline & Yes, internalizing (2) & - & - & - & - \\
\hline & Yes, externalizing (5) & 0.400 .19 to 0.61 ) & 1.54 & $0 \%$ & 0.82 \\
\hline & No (15) & $0.40(0.19$ to 0.60$)$ & 23.80 & $41 \%$ & 0.04 \\
\hline \multirow{2}{*}{$\begin{array}{l}\text { Experimental } \\
\text { paradigm }\end{array}$} & Flanker (22) & $0.43(0.27$ to 0.59$)$ & 31.92 & $34.2 \%$ & 0.04 \\
\hline & Go/no-go (5) & $0.46(-0.10$ to 1.01$)$ & 8.52 & $53 \%$ & 0.07 \\
\hline \multirow{2}{*}{$\begin{array}{l}\text { Performance } \\
\text { feedback }\end{array}$} & Yes (17) & $0.43(0.27$ to 0.58$)$ & 16.97 & $5.7 \%$ & 0.39 \\
\hline & No (10) & 0.47 (0.13 to 0.82$)$ & 23.61 & $61.9 \%$ & $<0.01$ \\
\hline
\end{tabular}




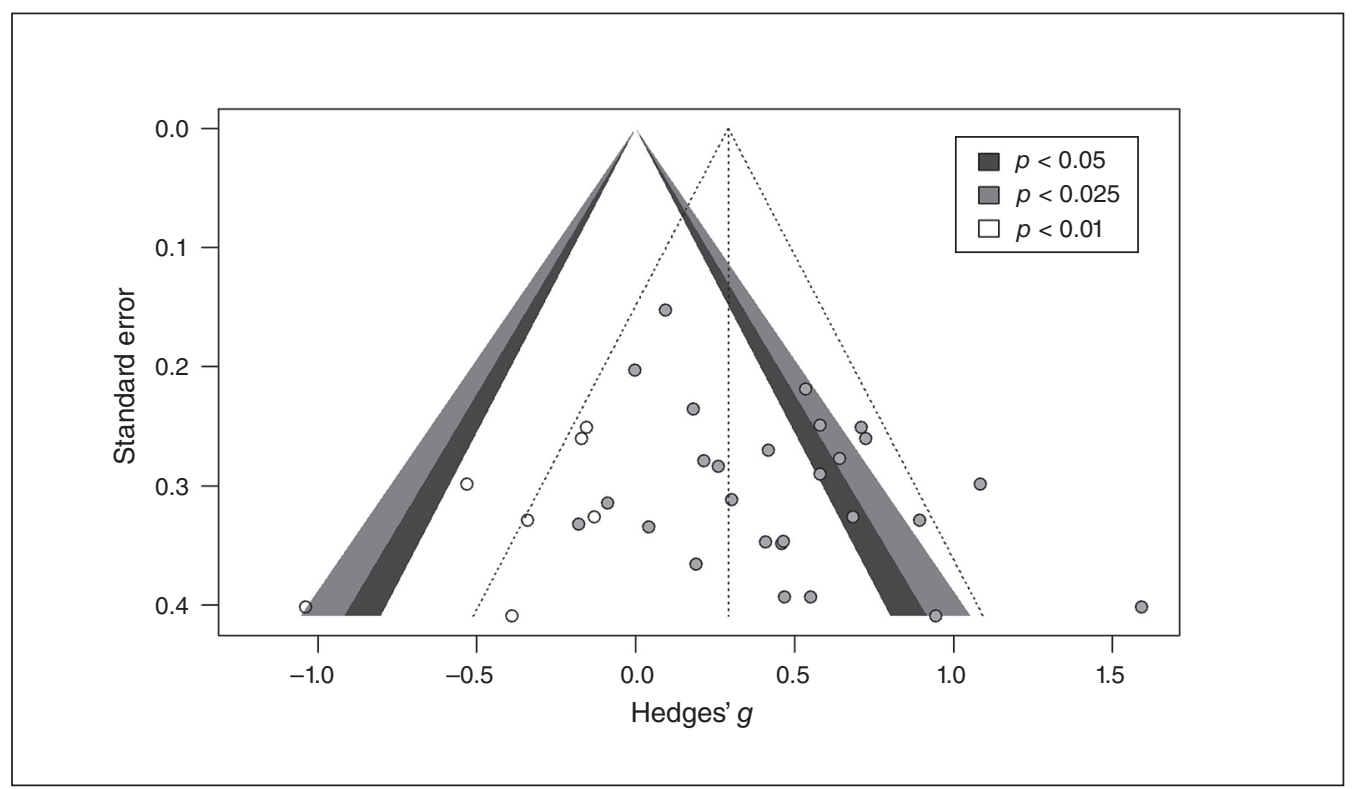

Figure 3: Funnel plot including filled studies for error-related negativity.

underpowered (25\%), typical in this field, it indicated that there was most likely no selective reporting of $p$ values. The $p$ curve estimate of the average "true" effect size was 0.32 , which was similar to the trim-and-fill result of 0.29 and lower than the combined effect size of the overall analysis (0.44). For a full report, including the disclosure table, a $p$ value distribution figure and results of the $p$ curve analysis, see Appendix 1, section 6 .

\section{Pe summary effect}

The Pe meta-analysis included 27 studies, incorporating 31 effect sizes and 1456 participants. We found a small to medium overall effect size $(g=-0.27,95 \%$ CI -0.44 to -0.09 , $p=0.004)$, indicative of decreased amplitude of the Pe waveform for the externalizing group compared to controls. We observed a moderate degree of heterogeneity $\left(I^{2}=52 \%, Q_{30}=\right.$ $62.74, p=0.004)$, which gave us cause for further exploration of effect size variability through subgroup analysis. A forest plot for the Pe is presented in Figure 4.

\section{Pe subgroup analysis}

Diagnosis was not a moderator for the Pe effect sizes $\left(Q_{4}=\right.$ $5.17, p=0.22)$, nor was comorbidity $\left(Q_{3}=1.61, p=0.66\right)$. The presence of feedback did not account for variability in Pe effect size $\left(Q_{1}=2.58, p=0.12\right)$. The experimental paradigm was a moderator in this meta-analysis. The go/no-go task generated a greater difference in Pe amplitudes (SMD $=-0.54, k=$ 9) than the Eriksen flanker task (SMD $=-0.15, k=22 ; Q_{1}=$ $4.17, p=0.041)$. Similar to the ERN, medication use was confounded in the ADHD sample, making further moderation analysis ineffective (Appendix 1, section 4). Age did not explain the variability in effect sizes for $\operatorname{Pe}\left(F_{1,27}=0.02, p=0.88\right)$. Table 3 shows the results of the moderation analysis for the categorical variables.

\section{Pe small sample study bias}

The Egger's intercept $(B=-2.45, p=0.019)$ was significant, indicating asymmetry in the funnel plot for the Pe studies. The funnel plot in Figure 5 includes studies that needed to be added to make the plot symmetrical using Duval and Tweedie's trim-and-fill procedure. This procedure revealed that by filling 5 studies, the overall effect was reduced $(g=$ $-0.15,95 \%$ CI -0.35 to 0.05$)$, meaning that the Pe metaanalysis could be contaminated by publication bias. However, the fail-safe $N$ assessment revealed that there needed to be 31 effect sizes to achieve the unweighted effect size of -0.16 . We performed a preliminary $p$ curve analysis, but it was inconclusive (see Appendix 1, section 6, for explanation).

\section{Discussion}

This meta-analysis collated current EEG studies on error processing to test whether the ERN and Pe amplitude were different in people with externalizing problems or disorders compared to controls. As expected, we found diminished ERN and Pe amplitude for people with externalizing problems or disorders compared to controls. These findings confirmed compromised error processing in the externalizing spectrum, regardless of a specific diagnosis or problem behaviour. For both ERP components, we found a considerable degree of heterogeneity. The variation in results was not explained by comorbidity, the presence of performance feedback, age or type of clinical disorder. The experimental paradigm was a moderator for the Pe studies, but not for the ERN studies. Our results for the ERN were in line with a recent meta-analysis by Pasion and Barbosa ${ }^{24}$ and studies that described error processing deficits in separate externalizing disorders (such as Luijten and colleagues ${ }^{7}$ and Olvet and Hajcak $^{20}$ for substance use disorders; Shiels and Hawk ${ }^{92}$ for 


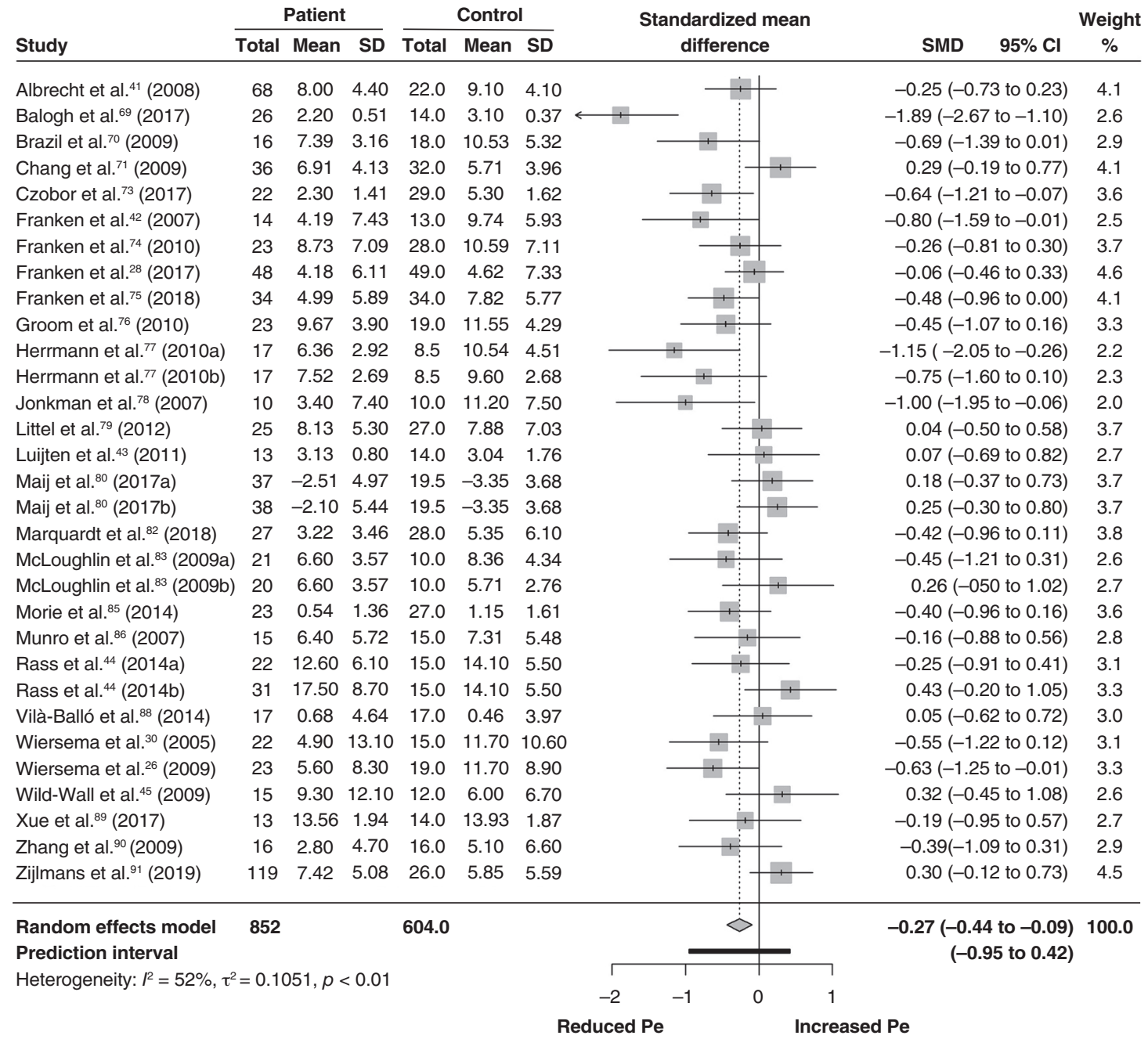

Figure 4: Overall Pe meta-analysis, including a forest plot. $\mathrm{Cl}=$ confidence interval; $\mathrm{Pe}=$ error positivity; $\mathrm{SD}=\mathrm{standard}$ deviation; $\mathrm{SMD}=$ standardized mean difference.

ADHD; and $\mathrm{Lo}^{6}$ for children with externalizing symptoms). This was the first meta-analysis to explore age effects in error processing and to confirm deficits in the late error processing component (Pe) for children and adults with externalizing problems and disorders.

Diminished ERN and Pe imply a deviant activation pattern of the dorsal anterior cingulate cortex. ${ }^{93}$ More specifically, when we consider reinforcement and learning-based theories of the function of the ERN, decreased ERN amplitude could be indicative of abnormal dopamine activity in the midbrain, affecting processes of error and conflict detection. Dysfunction in the dorsal anterior cingulate cortex is also indicative of deficits in inhibitory control and conflict monitoring. ${ }^{3,7,85}$ Problems in inhibitory control and conflict monitoring (among other cognitive impairments) have been related to symptomatology in externalizing disorders, such as craving in addiction. ${ }^{94}$ Based on the proposed hypotheses for $\mathrm{Pe}^{37}$ affected Pe amplitudes reflect differences in conscious recognition of the error committed, differences in emotional appraisal of the error and its consequences, or distinct behavioural adjustment after errors. In turn, such deviation in the processing of errors could imply reduced insight in aberrant and unwanted behaviour for externalizing samples.

The data revealed a considerable amount of heterogeneity for both ERPs, but type of diagnosis, age and the presence of performance feedback or comorbidity did not moderate the results. Studies that controlled for medication use in their samples appeared mostly to be in ADHD, preventing us from examining medication use across other externalizing samples. Although medication use is evident in externalizing samples, many studies have not reported or controlled for medication. Future experiments and systematic reviews 
Table 3: Results of multiple moderator analyses for Pe

\begin{tabular}{|c|c|c|c|c|c|}
\hline \multirow[b]{2}{*}{ Moderator } & \multirow[b]{2}{*}{ Categories $(k)$} & \multicolumn{4}{|c|}{$\mathrm{Pe}$} \\
\hline & & SMD $(95 \% \mathrm{Cl})$ & $Q$ & $1^{2}$ & $p$ value \\
\hline \multirow{5}{*}{$\begin{array}{l}\text { Clinical diagnosis } \\
\text { group }\end{array}$} & Child ADHD (7) & $-0.39(-0.70$ to -0.08$)$ & 6.04 & $0 \%$ & 0.42 \\
\hline & Adult ADHD (8) & $-0.56(-1.15$ to 0.04$)$ & 28.86 & $76 \%$ & $<0.01$ \\
\hline & Clinical addiction (5) & $-0.15(-0.66$ to 0.36$)$ & 6.81 & $41 \%$ & 0.15 \\
\hline & Subclinical addiction (5) & $-0.09(-0.40$ to 0.23$)$ & 5.9 & $15 \%$ & 0.30 \\
\hline & Other (6) & $-0.08(-0.55$ to 0.40$)$ & 6.14 & $35 \%$ & 0.19 \\
\hline \multirow[t]{4}{*}{ Comorbidity } & Yes, mixed (4) & $-0.23(-0.85$ to 0.40$)$ & 6.59 & $54 \%$ & 0.09 \\
\hline & Yes, internalizing (2) & - & - & - & - \\
\hline & Yes, externalizing (19) & $-0.07(-0.48$ to 0.34$)$ & 9.65 & $48 \%$ & 0.09 \\
\hline & No $(6)$ & $-0.28(-0.47$ to -0.10$)$ & 23.84 & $24 \%$ & 0.16 \\
\hline \multirow[t]{2}{*}{ Experimental paradigm } & Flanker (22) & $-0.15(-0.33$ to 0.04$)$ & 36.01 & $42 \%$ & 0.02 \\
\hline & Go/no-go (9) & $-0.53(-0.92$ to -0.15$)$ & 17.14 & $53 \%$ & 0.03 \\
\hline \multirow[t]{2}{*}{ Performance feedback } & Yes (20) & $-0.16(-0.34$ to 0.02$)$ & 28.40 & $33.1 \%$ & 0.08 \\
\hline & No (11) & $-0.47(-0.86$ to -0.08$)$ & 30.08 & $66.8 \%$ & $<0.01$ \\
\hline $\begin{array}{l}\text { ADHD = attention-deficit/hyp } \\
\text { SMD }=\text { standardized mean } \\
\text { Random models with moder } \\
\text { analyses to investigate the } e\end{array}$ & $\begin{array}{l}\text { ctivity disorder; } \mathrm{Cl}=\text { confide } \\
\text { rence. } \\
\text { s for } \mathrm{Pe} \text { studies, except for } \\
\text { t of other midline electrode }\end{array}$ & $\begin{array}{l}\text { erval; } k=\text { number of studi } \\
\text { izing comorbidity (fewer } t \\
\text { and } \mathrm{Cz} \text { (Appendix } 1, \mathrm{Se}\end{array}$ & dies). & form & $\begin{array}{l}\text { positivity } \\
\text { equent }\end{array}$ \\
\hline
\end{tabular}

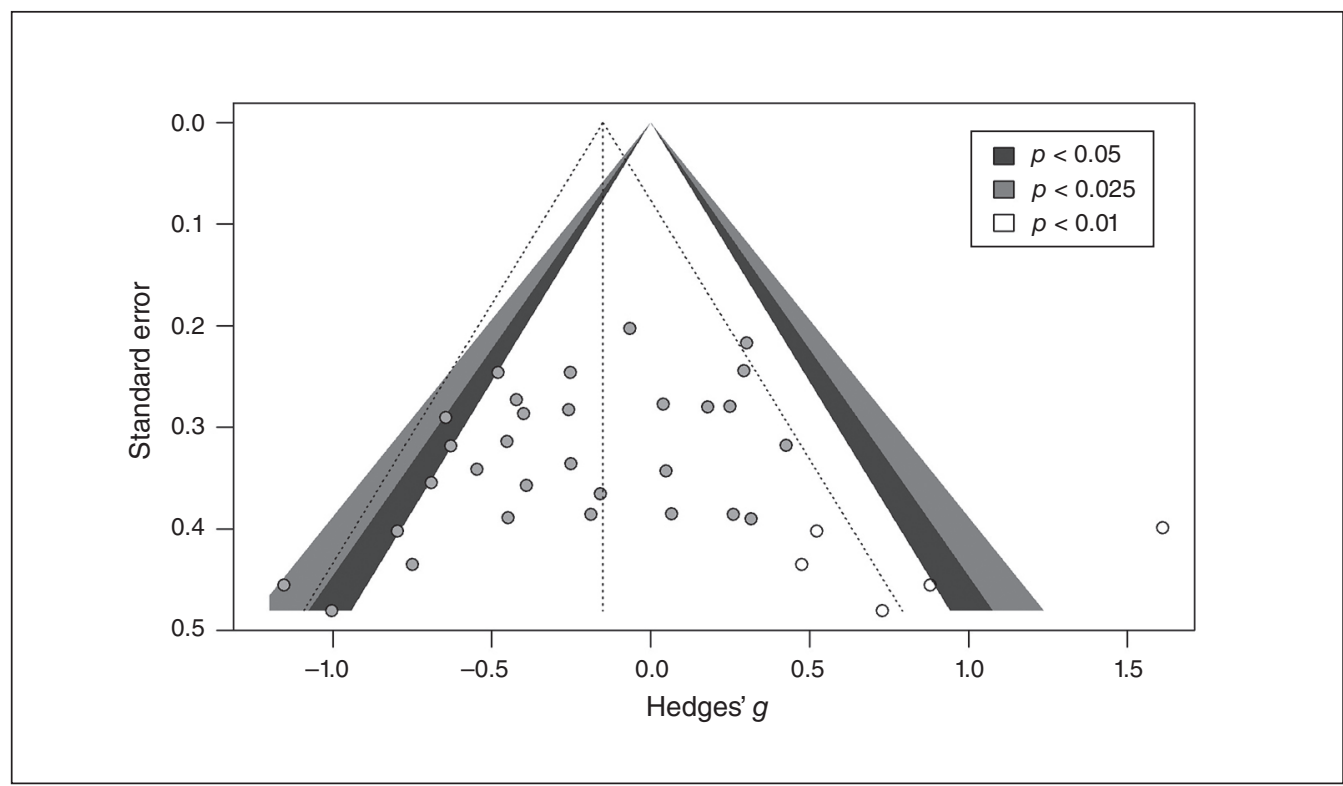

Figure 5: Funnel plot including filled studies for error positivity.

should consider the effect of medication on error processing components for different externalizing samples. The experimental task did moderate the association of externalizing problems with Pe and not ERN: we found a greater Pe amplitude difference between the patient group and the control group in the go/no-go task than in the Eriksen flanker task. Although both tasks are known to reliably elicit an electrophysiological reaction after an error, ${ }^{15,46}$ it is possible that the go/no-go task elicits a stronger reaction to an error than the Eriksen flanker task. As well, it is possible that the Eriksen flanker task allows the participant to be more unconscious of an error than the go/no-go task, because the Pe is said to reflect conscious awareness of the error. ${ }^{37}$ Finally, contrary to our expectations, comorbidity did not affect the ERN or Pe amplitude in this sample. Although we proposed to test whether internalizing comorbid problems influenced the ERPs, not enough studies were included to properly test this hypothesis and draw firm conclusions.

We performed small bias assessment to investigate the effect of the published data in this study. For the ERN, the result of the trim-and-fill procedure remained significant even after adding 5 studies. The estimated "true" effect size was 
included in the confidence interval of the overall model, along with evidence of the evidential value from the $p$ curve analysis, indicating that the combined effect size for the ERN was robust. However, for the $\mathrm{Pe}$, we found evidence of publication bias (although an inconclusive $p$ curve analysis), because the trim-and-fill analysis reduced the effect size to nonsignificant. Although this nonsignificant effect could have been because of large heterogeneity, reflected in the broad confidence interval, we should be cautious in drawing firm conclusions about the Pe meta-analysis.

\section{Limitations}

We should acknowledge the limitations of this study and the methodological considerations of EEG research in general. The present meta-analysis included studies with ERN amplitudes on the FCz electrode and Pe amplitudes on the $\mathrm{Cz}$ electrode, generated by the Eriksen flanker and go/nogo tasks. These criteria allowed for solid results (supplementary analysis revealed no effect of electrode site), but other electrodes (see Arbel and Donchin ${ }^{36}$ for a summary of reliable electrodes for error processing), neurophysiological measures (e.g., functional MRI) and experimental paradigms can be used to examine error processing. $\mathrm{Fu}-$ ture research should be directed at investigating whether similar error processing deficits are found at other electrode sites and using other tasks. In addition, investigating deficits in biobehavioural markers of performance monitoring, such as post-error slowing (indicative of response caution for maintaining accuracy) and cortisol involvement ${ }^{95}$ can shed light on responses and behaviour after errors, elucidating different behaviour patterns. Although we considered a substantial number of potential moderators in this study, other sample characteristics could have accounted for differences in the ERP findings. For example, the global assessment of functioning of patients with a specific psychiatric disorder could influence the magnitude of deficits in error processing. Future studies could examine whether the severity of symptoms within a disorder is related to the degree of diminished reaction (that is, correlational measures with ERP amplitudes). As well, individual differences such as personality traits have been known to influence the ERN and $\mathrm{Pe}^{6,37}$ and we did not control for these factors in this study. Furthermore, we should be cautious of the results (particularly indicated by the publication bias assessment) because of variations in quality in the EEG experiments. Although the current study evaluated the included experiments, differences between experiments could have influenced our results. We could not assess some aspects of experimental design, such as the manner in which the ERN or Pe were quantified or the effects of task adjustments, because this information was not provided in the reports. To address the possible effect of experimental design differences on the associations between ERP or Pe with externalizing problems in the future, we encourage researchers to disclose the following information: the minimum number of trials or errors for a reliable ERP calculation (e.g., $8^{16}$ or $6^{96}$ trials for a reliable ERN); which trials were used (incongruent or error trials) to calculate the ERP; and a clear description of the task instructions and adjustments (e.g., error rate to ensure task difficulty, participant instructions or feedback to influence performance); and other potential confounding variables such as medication use and latency window.

Future work could investigate error processing in specific externalizing disorders that are underexplored in the current literature, such as antisocial personality disorder, specific addictions (e.g., Internet addiction disorder) and double diagnoses (e.g., addiction and a personality disorder). We recommend that future work examine the predictive value of the ERN and Pe using large-scale longitudinal designs to elucidate their role in the etiology of these disorders. We also encourage researchers to assess the feasibility of interventions aimed at improving error processing. To improve error processing abilities in patients, next steps for future experiments could include examinations of the effectiveness of behavioural training, medication and neuromodulation techniques.

\section{Conclusion}

Our meta-analysis showed that the neurophysiological correlates of error processing, ERN and Pe, were reduced in children and adults with externalizing problems or disorders. However, we found considerable heterogeneity that could not be explained by the moderators explored in this study; this warrants further exploration and limits strong conclusions. Future research can elucidate the role of individual differences, symptom severity and experimental characteristics in error processing deficits specific to externalizing disorders. With the knowledge that the EEG correlates of error processing are affected in people with internalizing problems and could serve as a possible marker for these disorders, we propose that reduced ERN and Pe could be considered markers for the externalizing spectrum of disorders.

Acknowledgments: Thank you to Judith Gulpers for her comments on my literature search. Thank you to Peter Clayson for his answers on analysis questions. Thank you to Arnout Boot for his help in R. We are grateful to all of the authors who provided with additional information for this manuscript.

Affiliations: From the Department of Psychology, Education and Child Studies, Erasmus University Rotterdam, Rotterdam, the Netherlands (Lutz, Kok, Verveer, Malbec, Franken); the Department of Clinical, Neuro- and Developmental Psychology, Vrije Universiteit Amsterdam, HV Amsterdam, the Netherlands (Lutz, Koot, van Lier).

Funding: This work was supported by the Erasmus Initiatives for Vital Cities and Citizens, Erasmus University Rotterdam, the Netherlands.

\section{Competing interests: None declared.}

Contributors: M. Lutz, R. Kok, S. Koot and I. Franken designed the study. M. Lutz and I. Verveer acquired the data, which M. Lutz, M. Malbec and P. van Lier analyzed. M. Lutz wrote the article, which all authors reviewed. All authors approved the final version to be published and can certify that no other individuals not listed as authors have made substantial contributions to the paper. 
Content licence: This is an Open Access article distributed in accordance with the terms of the Creative Commons Attribution (CC BY-NC-ND 4.0) licence, which permits use, distribution and reproduction in any medium, provided that the original publication is properly cited, the use is noncommercial (i.e., research or educational use), and no modifications or adaptations are made. See: https://creativecommons.org/licenses/by-nc-nd/4.0/

\section{References}

1. Morgan $\mathrm{AB}$, Lilienfeld SO. A meta-analytic review of the relation between antisocial behavior and neuropsychological measures of executive function. Clin Psychol Rev 2000;20:113-36.

2. Luna B, Marek S, Larsen B, et al. An integrative model of the maturation of cognitive control. Annu Rev Neurosci 2015;38:151-70.

3. Ridderinkhof KR, Ullsperger M, Crone EA, et al. The role of the medial frontal cortex in cognitive control. Science 2004;306:443-7.

4. Krueger RF, South SC. Externalizing disorders: cluster 5 of the proposed meta-structure for DSM-V and ICD-11. Psychol Med 2009; 39:2061-70.

5. Holroyd CB, Coles MGH. The neural basis of human error processing: reinforcement learning, dopamine, and the error-related negativity. Psychol Rev 2002;109:679-709.

6. Lo SL. A meta-analytic review of the event-related potentials (ERN and N2) in childhood and adolescence: providing a developmental perspective on the conflict monitoring theory. Dev Rev 2018;48:82-112.

7. Luijten M, Machielsen MWJ, Veltman DJ, et al. Systematic review of ERP and fMRI studies investigating inhibitory control and error processing in people with substance dependence and behavioural addictions. J Psychiatry Neurosci 2014;39:149-69.

8. Gehring WJ, Goss B, Coles MGH, et al. A neural system for error detection and compensation. Psychol Sci 1993;4:385-90.

9. Gehring WJ, Goss B, Coles MGH, et al. The error-related negativity. Perspect Psychol Sci 2018;13:200-4.

10. Falkenstein M, Hohnsbein J, Hoormann J, et al. Effects of crossmodal divided attention on late ERP components. II. Error processing in choice reaction tasks. Electroencephalogr Clin Neurophysiol 1991;78:447-55.

11. Coles MGH, Scheffers MK, Holroyd CB. Why is there an ERN/Ne on correct trials? Response representations, stimulus-related components, and the theory of error-processing. Biol Psychol 2001;56:173-89.

12. Falkenstein $\mathrm{M}$, Hoormann J, Christ $\mathrm{S}$, et al. ERP components on reaction errors and their functional significance: a tutorial. Biol Psychol 2000;51:87-107.

13. Dehaene S, Posner MI, Tucker DM. Localization of a neural system for error detection and compensation. Society 2010;5:303-5.

14. Van Veen V, Carter CS. The timing of action-monitoring processes in the anterior cingulate cortex. J Cogn Neurosci 2002;14:593-602.

15. Riesel A, Weinberg A, Endrass T, et al. The ERN is the ERN is the ERN? Convergent validity of error-related brain activity across different tasks. Biol Psychol 2013;93:377-85.

16. Rietdijk WJR, Franken IHA, Thurik AR. Internal consistency of event-related potentials associated with cognitive control: N2/P3 and ERN/Pe. PLoS One 2014;9: e102672.

17. Hester R, Foxe JJ, Molholm S, et al. Neural mechanisms involved in error processing: a comparison of errors made with and without awareness. Neuroimage 2005;27:602-8.

18. Nieuwenhuis S, Ridderinkhof RK, Blom J, et al. Error-related brain potentials are differentially related to awareness of response errors: evidence from an antisaccade task. Psychophysiology 2001; 38:752-60.

19. Loo SK, Lenartowicz A, Makeig S. Use of EEG biomarkers in child psychiatry research-current state and future directions. J Child Psychol Psychiatry 2016;57:4-17.

20. Olvet DM, Hajcak G. The error-related negativity (ERN) and psychopathology: toward an endophenotype. Clin Psychol Rev 2008;28:1343-54.

21. Moser JS, Moran TIMP, Kneip C, et al. Sex moderates the association between symptoms of anxiety, but not obsessive compulsive disorder, and error-monitoring brain activity: a meta-analytic review. Psychophysiology 2016;53:21-9.
22. Riesel A. The erring brain: error-related negativity as an endophenotype for OCD - a review and meta-analysis. Psychophysiology 2019;56:e13348.

23. Moran TP, Schroder HS, Kneip C, et al. Meta-analysis and psychophysiology: a tutorial using depression and action-monitoring event-related potentials. Int J Psychophysiol 2017;111:17-32.

24. Pasion R, Barbosa F. ERN as a transdiagnostic marker of the internalizing-externalizing spectrum: a dissociable meta-analytic effect. Neurosci Biobehav Rev 2019;103:133-49.

25. Rudo-Hutt AS. Electroencephalography and externalizing behavior: a meta-analysis. Biol Psychol 2015;105:1-19.

26. Wiersema JR, Van Der Meere JJ, Roeyers H. ERP correlates of error monitoring in adult ADHD. J Neural Transm (Vienna) 2009;116:371-9.

27. Zhou Z, Li C, Zhu H. An error-related negativity potential investigation of response monitoring function in individuals with internet addiction disorder. Front Behav Neurosci 2013;7:131.

28. Franken IHA, Luijten M, van der Veen FM, et al. Cognitive control in young heavy drinkers: an ERP study. Drug Alcohol Depend 2017; 175:77-83.

29. Van De Voorde S, Roeyers H, Wiersema JR. Error monitoring in children with ADHD or reading disorder: an event-related potential study. Biol Psychol 2010;84:176-85.

30. Wiersema JR, van der Meere JJ, Roeyers H. ERP correlates of impaired error monitoring in children with ADHD. J Neural Transm (Vienna) 2005;112:1417-30.

31. Schellekens AFA, de Bruijn ERA, van Lankveld CAA, et al. Alcohol dependence and anxiety increase error-related brain activity. Addiction 2010;105:1928-34.

32. Groom MJ, Liddle EB, Scerif G, et al. Motivational incentives and methylphenidate enhance electrophysiological correlates of error monitoring in children with attention deficit/hyperactivity disorder. J Child Psychol Psychiatry 2013;54:836-45.

33. Grützmann R, Endrass T, Klawohn J, et al. Response accuracy rating modulates ERN and Pe amplitudes. Biol Psychol 2014;96:1-7.

34. Hajcak G, Moser JS, Yeung N, et al. On the ERN and the significance of errors. Psychophysiology 2005;42:151-60.

35. Riesel A, Weinberg A, Endrass T, et al. Punishment has a lasting impact on error-related brain activity. Psychophysiology 2012;49:239-47.

36. Arbel Y, Donchin E. Parsing the componential structure of posterror ERPs: a principal component analysis of ERPs following errors. Psychophysiology 2009;46:1179-89.

37. Overbeek TJM, Nieuwenhuis S, Ridderinkhof KR. Dissociable components of error processing: on the functional significance of the Pe vis-à-vis the ERN/Ne. J Psychophysiol 2005;19:319-29.

38. Davies PL, Segalowitz SJ, Dywan J, et al. Error-negativity and positivity as they relate to other ERP indices of attentional control and stimulus processing. Biol Psychol 2001;56:191-206.

39. Ridderinkhof KR, Ramautar JR, Wijnen JG. To PE or not to PE: a P3-like ERP component reflecting the processing of response errors. Psychophysiology 2009;46:531-8.

40. Herrmann MJ, Römmler J, Ehlis AC, et al. Source localization (LORETA) of the error-related-negativity (ERN/Ne) and positivity (Pe). Brain Res Cogn Brain Res 2004;20:294-9.

41. Albrecht $\mathrm{B}$, Brandeis $\mathrm{D}$, Uebel $\mathrm{H}$, et al. Action monitoring in boys with attention-deficit/hyperactivity disorder, their nonaffected siblings, and normal control subjects: evidence for an endophenotype. Biol Psychiatry 2008;64:615-25.

42. Franken IHA, van Strien JW, Franzek EJ, et al. Error-processing deficits in patients with cocaine dependence. Biol Psychol 2007;75:45-51.

43. Luijten M, Van Meel CS, Franken IHA. Diminished error processing in smokers during smoking cue exposure. Pharmacol Biochem Behav 2011;97:514-20.

44. Rass O, Fridberg DJ, O'Donnell BF. Neural correlates of performance monitoring in daily and intermittent smokers. Clin Neurophysiol 2014;125:1417-26.

45. Wild-Wall N, Oades RD, Schmidt-Wessels M, et al. Neural activity associated with executive functions in adolescents with attentiondeficit/hyperactivity disorder (ADHD). Int J Psychophysiol 2009; 74:19-27.

46. Segalowitz SJ, Santesso DL, Murphy TI, et al. Retest reliability of medial frontal negativities during performance monitoring. Psychophysiology 2010;47:260-70. 
47. Siddaway AP, Wood AM, Hedges LV. How to do a systematic review: a best practice guide for conducting and reporting narrative reviews, meta-analyses, and meta-syntheses. Annu Rev Psychol 2019; 70:747-70.

48. Eriksen BA, Eriksen CW. Effects of noise letters upon the identification of a target letter in a nonsearch task. Percept Psychophys 1974;16:143-9.

49. Viechtbauer W. Bias and efficiency of meta-analytic variance estimators in the random-effects model. J Educ Behav Stat 2005;30:261-93.

50. Novianti PW, Roes KCB, van der Tweel I. Estimation of between-trial variance in sequential meta-analyses: a simulation study. Contemp Clin Trials 2014;37:129-38.

51. Veroniki AA, Jackson D, Viechtbauer W, et al. Methods to estimate the between-study variance and its uncertainty in meta-analysis. Res Synth Methods 2016;7:55-79.

52. Hedge LV. Distribution theory for Glass's estimator of effect size and related estimators. J Educ Stat 1981;6:107-28.

53. Harrer M, Cuijpers P, Furukawa TA, et al. Doing meta-analysis in R: a hands-on guide. Boca Raton (FL): CRC Press; 2019.

54. Cohen J. Statistical power analysis for the behavioral sciences. New York: Academic Press; 1977.

55. Viechtbauer W, Cheung MW. Outlier and influence diagnostics for meta-analysis. Res Synth Methods 2010;1:112-25.

56. Higgins JPT, Thompson SG. Quantifying heterogeneity in a metaanalysis. Stat Med 2002;21:1539-58

57. Higgins JPT, Thompson SG, Deeks JJ, et al. Measuring inconsistency in meta-analyses. BMJ 2003;327:557-60.

58. Egger M, Smith GD, Schneider M, et al. Bias in meta-analysis detected by a simple, graphical test. BMJ 1997;316:1-18.

59. Duval S, Tweedie R. Trim and fill: a simple funnel-plot-based method. Biometrics 2000;56:455-66.

60. Zwetsloot P-P, Van Der Naald M, Sena ES, et al. Standardized mean differences cause funnel plot distortion in publication bias assessments. eLife 2017;6:e24260.

61. Orwin RG. A fail-safe $\mathrm{N}$ for effect size in meta-analysis. J Educ Behav Stat 1983;8:157-9.

62. Simonsohn U, Nelson LD, Simmons JP. P-curve: a key to the filedrawer. J Exp Psychol Gen 2014;143:534.

63. Simonsohn U, Nelson LD, Simmons JP. P-curve and effect size: correcting for publication bias using only significant results. Perspect Psychol Sci 2014b;9:666-81.

64. Simonsohn U, Simmons JP, Nelson LD. Better p-curves: making pcurve analysis more robust to errors, fraud, and ambitious p-hacking, a reply to Ulrich and Miller. J Exp Psychol Gen 2015;144:1146-52.

65. Clayson PE, Carbin KA, Larson MJ. A registered report of errorrelated negativity and reward positivity as biomarkers of depression: p-curving the evidence. Int J Psychophysiol 2020;150:50-72.

66. Van Aert RC, Wicherts JM, van Assen MALM. Conducting metaanalyses based on $p$ values: reservations and recommendations for applying p-uniform and p-curve. Perspect Psychol Sci 2016;11:713-29.

67. Schwarzer G. Meta: an R package for meta-analysis. R News 2007; 7:40-5.

68. Viechtbauer W. Conducting meta-analysis in $\mathrm{R}$ with the metafor package. J Stat Softw 2010;36:1-48.

69. Balogh L, Kakuszi B, Papp S, et al. Neural correlates of error monitoring in adult attention deficit hyperactivity disorder after failed inhibition in an emotional go/no-go task. J Neuropsychiatry Clin Neurosci 2017;29:326-33.

70. Brazil IA, de Bruijn ERA, Bulten BH, et al. Early and late components of error monitoring in violent offenders with psychopathy. Biol Psychiatry 2009;65:137-43.

71. Chang WP, Davies PL, Gavin WJ. Error monitoring in college students with attention-deficit/hyperactivity disorder. J Psychophysiol 2009;23:113-25.

72. Chen H, Jiang H, Guo Q, et al. Case-control study of error-related negativity among males with heroin dependence undergoing rehabilitation. Shanghai Jingshen Yixue 2013;25:141-8.
73. Czobor P, Kakuszi B, Németh K, et al. Electrophysiological indices of aberrant error-processing in adults with ADHD: a new region of interest. Brain Imaging Behav 2017;11:1616-28.

74. Franken IHA, van Strien JW, Kuijpers A. Evidence for a deficit in the salience attribution to errors in smokers. Drug Alcohol Depend 2010;106:181-5.

75. Franken IHA, Nijs IMT, Toes A, et al. Food addiction is associated with impaired performance monitoring. Biol Psychol 2018;131:49-53.

76. Groom MJ, Cahill JD, Bates AT, et al. Electrophysiological indices of abnormal error-processing in adolescents with attention deficit hyperactivity disorder (ADHD). J Child Psychol Psychiatry 2010;51:66-76.

77. Herrmann MJ, Mader K, Schreppel T, et al. Neural correlates of performance monitoring in adult patients with attention deficit hyperactivity disorder (ADHD). World J Biol Psychiatry 2010;11:457-64.

78. Jonkman LM, van Melis JJM, Kemner C, et al. Methylphenidate improves deficient error evaluation in children with ADHD: an event-related brain potential study. Biol Psychol 2007;76:217-29.

79. Littel M, Van Den Berg I, Luijten M, et al. Error processing and response inhibition in excessive computer game players: an eventrelated potential study. Addict Biol 2012;17:934-47.

80. Maij DLR, van de Wetering BJM, Franken IHA. Cognitive control in young adults with cannabis use disorder: an event-related brain potential study. J Psychopharmacol 2017;31:1015-26.

81. Marhe R, Van De Wetering BJM, Franken IHA. Error-related brain activity predicts cocaine use after treatment at 3-month follow-up. Biol Psychiatry 2013;73:782-8.

82. Marquardt L, Eichele H, Lundervold AJ, et al. Event-related-potential (ERP) correlates of performance monitoring in adults with attentiondeficit hyperactivity disorder (ADHD). Front Psychol 2018;9:485.

83. McLoughlin G, Albrecht B, Banaschewski T, et al. Performance monitoring is altered in adult ADHD: a familial event-related potential investigation. Neuropsychologia 2009;47:3134-42.

84. Michelini G, Kitsune GL, Cheung CHM, et al. Attention-deficit/ hyperactivity disorder remission is linked to better neurophysiological error detection and attention-vigilance processes. Biol Psychiatry 2016;80:923-32.

85. Morie KP, De Sanctis P, Garavan H, et al. Executive dysfunction and reward dysregulation: a high-density electrical mapping study in cocaine abusers. Neuropharmacology 2014;85:397-407.

86. Munro GES, Dywan J, Harris GT, et al. ERN varies with degree of psychopathy in an emotion discrimination task. Biol Psychol 2007;76:31-42.

87. Sokhadze E, Stewart C, Hollifield M, et al. Event-related potential study of executive dysfunctions in a speeded reaction task in cocaine addiction. J Neurother 2008;12:185-204.

88. Vilà-Balló A, Hdez-Lafuente P, Rostan C, et al. Neurophysiological correlates of error monitoring and inhibitory processing in juvenile violent offenders. Biol Psychol 2014;102:141-52.

89. Xue J-M, Lin P-Z, Sun J-W, et al. Disrupted executive function and aggression in individuals with a history of adverse childhood experiences: an event-related potential study. J Nero Ment Dis 2017;205:942-51.

90. Zhang JS, Wang Y, Cai RG, et al. The brain regulation mechanism of error monitoring in impulsive children with ADHD - an analysis of error related potentials. Neurosci Lett 2009;460:11-5.

91. Zijlmans J, Bevaart F, van Duin L, et al. Error-related brain activity in relation to psychopathic traits in multi-problem young adults: an ERP study. Biol Psychol 2019;144:46-53.

92. Shiels K, Hawk LW. Self-regulation in ADHD: the role of error processing. Clin Psychol Rev 2010;30:951-61.

93. Botvinick MM, Cohen JD, Carter CS. Conflict monitoring and anterior cingulate cortex: an update. Trends Cogn Sci 2004;8:539-46.

94. Czermainski FR, Willhelm AR, Santos ÁZ, et al. Assessment of inhibitory control in crack and/or cocaine users: a systematic review. Trends Psychiatry Psychother 2017;39:216-25.

95. Tops M, Boksem MAS. Cortisol involvement in mechanisms of behavioral inhibition. Psychophysiology 2011;48:723-32.

96. Olvet DM, Hajcak G. The stability of error-related brain activity with increasing trials. Psychophysiology 2009;46:957-61. 